\title{
Racionalidade capitalista e a crise da razão: reflexões sobre a sustentabilidade e a questão socioambiental mundial contemporânea
}

capitalist rationality and the rationality crisis: reflections about sustainability and the world contemporary socioenvironmental question

\author{
Sandro Haoxovell de Lira', Daniel Carneiro Costa², Therezinha de Jesus Pinto Fraxe \\ 'Universidade Federal do Amazonas, Técnico-administrativo em Educação do Instituto de Saúde e Biotecnologia de Coari-AM (ISB-UFAM) \\ 2 Técnico-Administrativo em Educação da Universidade Federal do Amazonas (UFAM) \\ ${ }^{3}$ Professora Associada da Universidade Federal do Amazonas, coordenadora do Núcleo de Socioeconomia (NUSEC-FCA-UFAM) \\ e coordenadora do Programa de Pós-Graduação em Ciências do Ambiente e Sustentabilidade na Amazônia (PPGCASA-UFAM).
}

\begin{abstract}
Resumo
As transformações ocorridas nas últimas décadas demandam um olhar mais crítico no sentido de análise e entendimento dos fenômenos envolvendo a sustentabilidade do desenvolvimento como objetivo comum da humanidade diante da crescente degradação socioambiental em escala planetária. A compreensão sistêmica da crise socioambiental passa necessariamente pela prerrogativa da análise da racionalidade produtiva capitalista, com vista à expansão intensiva e progressiva do processo produtivo, da obtenção de lucros a qualquer custo e da centralização da riqueza socialmente produzida (em detrimento dos processos socioecológicos), bem como a dos limites biofísicos dos ecossistemas da Terra. Para isso, torna-se imprescindível a articulação da razão econômica vigente e da capacidade de suporte dos sistemas ecológicos do planeta para melhor entendimento dos principais entraves para consecução da sustentabilidade do desenvolvimento, como alternativa de enfrentamento da crise ambiental e social na contemporaneidade. Esse enfrentamento, portanto, se dará por um movimento sociopolítico a partir dos Países do Sul em contraposição às cadeias hegemônicas impostas pelos Países Centrais.
\end{abstract}

Palavras Chave: racionalidade de mercado, sustentabilidade, crise socioambiental, racionalidade alternativa ambiental, crise da razão.

\begin{abstract}
The changes occurred in the last decades requires an critical view related to the analysis and understanding of the facts involving the sustainability of the development with the common objective of the humanity facing the growing socioenvironmental degradation in global scale. The systemic comprehension of the socioenvironmental crisis goes necessarily through the prerogative of the analysis of the capitalist productive rationality, seeking to the intensive and progressive expansion of the productive process, of the generation of profits no matter what it takes to and of the centralization of socially produced wealth (in detriment of socioecological process), as well as of the biophysical limits of earth's ecosystems. To do that, is indispensable a link between the established economic rationality and the carrying capacity of the ecological systems of our planet to have a better comprehension of the mains obstacles to the achievement of the sustainable development, as an alternative of confrontation of the socioenvironmental crisis in our times. This confrontations, therefore, will be given by a sociopolitical movement initiated in the developing countries against the hegemonic chains imposed by the developed ones.

Keywords: market rationality, sustainability, socioenvironmental crisis, environmental alternative rationality, rationality crisis.
\end{abstract}




\section{INTRODUÇÃO}

A Racionalidade Ambiental, concebida como proposta sistêmica de desenvolvimento capaz de suceder a Razão dominante global, ganhou importância estratégica perante o agravamento da problemática socioambiental planetária. $\mathrm{O}$ debate referente à crise ambiental se intensificou nas últimas décadas em função dos questionamentos acerca do caráter insustentável dos padrões de consumo excessivos e altamente destruidores de recursos naturais localizados em todo globo terrestre.

Este processo vem comprometendo o equilíbrio planetário em todos os seus aspectos, uma vez que se consolida à custa da redução da biodiversidade - comprometendo diversos ecossistemas - e da sujeição de culturas e modos de vida à homogeneização impiedosa definida pela lógica produtiva capitalista altamente concentradora de riqueza socialmente produzida.

A consideração de que o atual parâmetro de desenvolvimento não é capaz de contemplar as múltiplas sociedades, além de estar baseado na exclusão social, concentração de riqueza e degradação ambiental, começou a ganhar força desde a década de 60 do Século XX. No entanto, a conjuntura mundial de então, marcada pela Guerra Fria, inviabilizava a apreciação devida que surgia com a proposta do chamado ecodesenvolvimento.

Esta proposta, inicialmente voltada para a promoção do desenvolvimento das regiões rurais dos países pobres, afirmou-se gradativamente como uma alternativa teórica, ética, política e econômica capaz de conciliar crescimento econômico com preservação ambiental, participação social, valorização cultural, dentre outros fundamentos.

Esta inovação se respaldava na constatação da capacidade histórica dos povos tradicionais das regiões tropicais de se reproduzir e se desenvolver numa relação complementar com seu ambiente natural. Desta maneira, as bases constituintes do que viria ser conhecido posteriormente como desenvolvimento sustentável iam sendo estudadas e alicerçadas como uma outra visão oposta aos ditames da razão arrogante e sua racionalidade de mercado (pelo menos no plano ideoteórico).

\section{METODOLOGIA}

Este artigo foi construído a partir de uma revisão bibliográfica e utiliza da pesquisa em literatura especializada em autores que discutem os processos de sustentabilidade global, bem como estudam e analisam a problemática socioambiental planetária e a crise da racionalidade dominante capitalista e suas contradições para a consecução da sustentabilidade do desenvolvimento.

\section{RESULTADOS E DISCUSSÃO}

\section{A Racionalidade capitalista e a problemática socioambiental}

As mudanças introduzidas no processo de modernização da sociedade, particularmente a partir da Revolução Industrial (ocorrida seminalmente na Inglaterra e depois socializada ao mundo inteiro), inauguraram novas modalidades de organização sociopolítica, econômica e ideológica do processo produtivo e novas configurações de apropriação dos recursos ambientais, que passa a ocorrer de maneira mais acelerada, mais intensiva e proporcionalmente maior em relação às temporalidades humanas anteriores.

As atividades antropogênicas, portanto, imprimiram uma inovada modalidade de produção e também de consumo de recursos naturais, culminando em emissão crescente de gases de efeito estufa, poluição da água, solo, sem mencionar em outras formas de degradação e pressão sobre os ecossistemas e a própria degradação da condição humana em forma de miséria, pauperismo, fome, desemprego e subemprego, desigualdades sociais e outras formas de precarização da vida humana, sob a justificativa do acúmulo e centralização da riqueza socialmente produzida imposta pela nova ordem societária.

Dessa forma, "[...] o processo de produção da pobreza e degradação socioambiental é gerado pela racionalidade econômica prevalecente" (LEFF, 2006, p. 480). O entendimento das dinâmicas introduzidas pela Revolução Industrial, cujo primeiro momento ocorre na fase do ferro e a segunda na fase do aço, é fundamental para se pensar a deterioração socioambiental e a crise ecológica mundial atuais.

A compreensão do ecodesenvolvimento como desdobramento da concepção da Racionalidade Ambiental requer, no entanto, o conhecimento da própria natureza da racionalidade dominante, que diz respeito à lógica do modo de produção capitalista. Esta lógica submete todas as dimensões da vida e da natureza às exigências quantitativas do mercado. A racionalidade capitalista, assim, ignora que o ambiente natural é uma condição indispensável para qualquer processo econômico. Esta racionalidade procura tratá-1o como mero fator de produção, como um objeto 
a ser dominado e manipulado, crendo que sua finitude pode ser compensada pelos avanços e benefícios tecnológicos. É um ilusório e terrível engano, cujos resultados globais começam a se fazer cada vez mais perceptíveis. $\mathrm{O}$ desenvolvimento calcado nesta racionalidade capitalista trouxe $o$ progresso técnico e o compromisso com a extinção das desigualdades, conforme Sachs (2004).

Este desenvolvimento supostamente eliminaria a distância existente entre os países centrais do capitalismo e sua periferia apartada socialmente. Para tanto, a modernidade tecnológica e científica seriam a redenção da condição humana. No entanto, esta concepção consolidou-se por meio da concentração de poder e riqueza. A produção econômica, cuja dinâmica se volta para as necessidades do mercado, procurou simplificar todas as culturas e ecossistemas à condição de mercadoria. E esta simplificação vem ocasionando desequilíbrios avassaladores crescentes.

A ponderação de Sachs $(2008$, p. 32) a respeito das "Idéias Sustentáveis" ilustra o quanto a produção econômica poderia ser sustentável caso considerasse devidamente o ambiente natural, bem como a diversidade cultural dos povos. Em outras palavras, a produção econômica capitalista procura reduzir a diversidade social, cultural e ecológica às necessidades estruturais e imediatas do mercado. Enfim, elimina a qualidade em benefício da quantidade.

Stahel (1995, p.108), ao comentar os trabalhos de Adam Smith referentes à "mão invisível" para fundamentar a ideologia capitalista, faz uma observação acerca do predomínio do critério quantitativo sobre o critério qualitativo: "Vamos apenas lembrar que ela pressupõe a redutibilidade da qualidade à quantidade, uma vez que o bem-estar geral (uma qualidade) seria a conseqüência de um sistema e de ações calcadas e dirigidas pelo mercado (critérios quantitativos)".

Em função desta lógica dominante produtiva, baseada no modo de produção capitalista, impõe-se um ritmo de produção de mercadorias que atenda às necessidades de acumulação e reprodução do capital. Ou seja, a sociedade industrial necessita fundamentalmente para a sua produção e reprodução usar e explorar crescentemente as bases materiais ecológicas da Gaia, entendido como planeta vivo e dotado de muitas partes interdependentes, constituindo um todo complexo que se autorregula (LOVELOCK, 2006).

O ritmo da sociedade industrial e sua razão arrogante, no entanto, é incompatível com o ritmo natural de regeneração, autorregulação e transformação dos processos ecológicos. Este tempo natural de recomposição da Gaia independe da interferência humana, ou seja, muito menos do tempo social de produção capitalista. Justamente diante de tal gravidade este autor considera a funcionalidade fisiológica deste organismo vivo para que se tenha uma adequada compreensão de sua dimensão.

Gaia é o nome da Terra entendida como um sistema fisiológico único, uma entidade que é viva pelo menos até o ponto em que, assim como os outros organismos vivos, os seus processos químicos e a sua temperatura regulam-se automaticamente em um estado favorável aos seus habitantes (LOVELOCK, 2006, p.12).

É neste contexto que a nossa morada sistêmica está sendo profundamente exaurida pelo processo exploratório e desenfreado de seus recursos, de suas fontes energéticas, prejudicando sua capacidade reprodutiva e autorregulatória natural, sendo, pois, a sociedade de mercado e do culto ao consumo a grande responsável por tal feito. E, por conta desta interferência brusca e racional realizada pela necessidade de acumulação e expansão capitalista, as alterações dos ciclos ecológicos vêm se traduzindo em mudanças climáticas, que ameaçam a experiência humana, numa escala sem precedentes históricos. A problemática central que se coloca hoje sobre a questão ecológica mundial pode ser traduzida da seguinte forma:

Se a Terra é um sistema ecológico fechado e vivo, com vários subsistemas que a compõe, com recursos finitos, como se dará a conjugação da pretensa sustentabilidade (em todas as suas modalidades: social, econômica, política, cultural e ambiental) com o modo de produção capitalista, que não vislumbra limites à sua expansão?

A resposta para este problema não é de fácil desvelamento e realização, nem tampouco objetivamente a sua resolução por ser demasiado complexa, pois não há soluções fáceis para questões complexas como esta que se apresenta sobre a sustentabilidade.

Todavia, ousaremos aqui elencar alguns pontos indispensáveis nessa discussão:

Primeiro porque a sustentabilidade do desenvolvimento é impraticável dentro da lógica capitalista, pois o modelo de desenvolvimento alavancado meramente pelo aspecto econômico, desprezando os campos ambiental e social não merece a nomeação de desenvolvimento sustentável (SACHS, 2008). Seria, então, o caso satanizar o capitalismo? Certamente, não. Pois a sociedade 
de mercado também trouxe importantes avanços, sobretudo nas áreas de medicina, agricultura, saneamento e comunicações e outras tecnologias que, se postas a serviço da humanidade e não do capital, constituem aspectos imprescindíveis para a sustentabilidade que se pretende alcançar. Então, pode-se dizer que o grande problema não está no capitalismo em si, mas na racionalidade dessa ordem mundial de acumulação, ou seja, na sua razão intensiva, progressiva e expansiva com fins a produção de lucro sem limites e sua privatização e a qualquer custo, que é a sua força motriz.

Por isso, emerge a necessidade urgente de, como bem indicou Santos (2001) em sua obra "Por uma outra globalização: do pensamento único a consciência universal", onde a base material da sociedade de consumo usada para circular capital fosse convertida para veicular valores humanos, onde a solidariedade fosse introduzida num nível de possibilitar intercâmbio pacífico e cooperação entre os povos, sem descartar a base técnica que dá sustentação a globalização econômica e financeira.

Segundo porque a resolução desta questão reside em diversas alternativas teórico-práticas nos campos econômico, social, cultural, territorial e político, que, aliás, acreditamos ser o nosso maior desafio contemporâneo, o uso de alternativas economicamente viáveis, politicamente corretas e socialmente justas na superação da crise ecológica. Nesse sentido, afirma-se antes de a crise ser de natureza socioecológica, trata-se de uma crise da razão do mercado, que corrompe e explora não somente o ambiente e sua capacidade de suporte, mas a sociedade em si que pouco se desenvolve em condições humanas, e aleija politicamente a sociedade por suas ideologias falseadoras do real.

A questão ambiental aparece como um sintoma da crise da razão da civilização moderna, como uma crítica da racionalidade social e do estilo de desenvolvimento dominantes, e como uma proposta para fundamentar um desenvolvimento alternativo (LEFF, 2001, p. 138).

A racionalidade produtiva capitalista atende a uma lógica racional expansiva, que Karl Marx com maestria clarificou denominando de "circuito do capital", que se dá pela seguinte composição D-M-D' (MARX, 1975, p. 165-175 apud STAHEL, 1995), onde D representa dinheiro, M representa mercadoria e D' significa obtenção de mais dinheiro. Ou seja, o dinheiro possibilita a produção ou compra de mercadoria e esta possibilita a aquisição de mais dinheiro, num movimento progressivo, dinâmico e infinito de acumulação de capital e pela civilização do consumo.

Se nas sociedades pré-capitalistas e tradicionais as relações se moldavam por meio da solidariedade, empréstimo de animais, na troca de produtos e no auxílio mútuo entre parentes e amigos, numa rede de proteção social comunal, em que o trabalho e a aquisição de bens necessários à reprodução material e simbólica ocorreria sem intenções de acúmulo e fora das lógicas mercantis, nas sociedades capitalistas essa lógica muda profundamente, pois o trabalho humano, tido como função social, antes estava atrelado a "reprodução simples" (biológica) e a "reprodução de vínculos, dos valores e das crenças", converte-se em trabalho como atividade de lucro (BOURDIEU, 1979, p. 33), aniquilando as outras formas de organização social, culturas, éticas e modos vida intrinsecamente ligados aos sistemas ecológicos complexos e aos símbolos e signos oriundos desse vínculo, numa imposição cruel de tentar converter tudo a sua imagem e semelhança.

A retórica dominante surge pelo impulso compulsivo à lucratividade com fruto da exploração do trabalho humano e ao culto exagerado pelo consumismo de recursos naturais e até de bens simbólicos inserido nessa lógica, repercutindo incisivamente sobre o ambiente e os processos societários.

Esse movimento compulsivo, que está na base estrutural epistemológica do grande capital, pode ser melhor explicitado assim:

A busca de expansão constante é, assim, inerente ao próprio capitalismo, ou, nas palavras de Marx, "A circulação de dinheiro como capital, ao contrário, tem sua finalidade em si mesma, pois a expansão do valor só existe nesse movimento continuamente renovado. Por isso, o movimento do capital não tem limites" (MARX, 1975, p. 171 apud STAHEL 1995, p. 107).

Este é o princípio básico da produção e reprodução do modo capitalista: crescer sem limites. Inclusive essa tem sido a retórica constante dos economistas, sobretudo no que se refere ao fato de que para a resolução de todos os males societários, inclusive os ambientais, o crescimento econômico deve ser mantido a qualquer custo, mesmo em detrimento dos aspectos socioambientais, políticos e culturais da humanidade. Sendo, dentro dessa lógica, o crescimento econômico a primeira condição para o sucesso dos demais campos da vida humana. 
O crescimento para a maioria dos economistas é tão essencial como o ar que respiramos: seria, dizem, a única força capaz de tirar os pobres da pobreza, de alimentar a crescente população mundial, de enfrentar os custos crescentes dos gastos públicos e de estimular o desenvolvimento tecnológico - isso sem mencionar o financiamento de estilos de vida cada vez mais caros. Eles não vêem limites ao crescimento, nunca (SACHS, LOPES e DOWBOR, 2010, p. 134).

Infelizmente, tal modelo de desenvolvimento alicerçado sobre o exclusivo aspecto econômico tem demonstrado historicamente uma falibilidade em relação às esferas sociais e ambientais. Afinal, o crescimento econômico mundial é inegável, todavia as disparidades sociais e as convulsões a que são submetidos os sistemas ecológicos demonstram quão equivocados estão os defensores dessa idéia fragmentária de enxergar o mundo. Além de não considerar o aspecto holístico e sistêmico, que representa uma visão abrangente, complexa e interdependente dos sistemas ecológicos e sociais globais, incluindo a cultura e a política com indispensáveis, onde estes sistemas funcionam como uma rede, nunca isolados do todo complexo.

Particularmente sobre essa visão econômica reducionista, Ianni (1991) desvela essa questão ao afirmar que a economia da sociedade brasileira de 1940 a 1980 cresceu catorze vezes, tornando-se uma das mais fortes e sólidas economias do mundo, mas a distribuição de renda permaneceu marcadamente desigual para a maior parte da população do país. Inclusive aponta que apesar de a economia nacional ser altamente diversificada, moderna e industrializada, como as nações européias, temos uma sociedade vivendo semelhantemente às mais empobrecidas e atrasadas populações afro-asiáticas. Segue o autor falando que um dos grandes problemas do Brasil é o seu profundo dualismo: país rico e pobre ao mesmo tempo, coexistindo num mesmo contexto.

Outros equívocos de que com um determinado crescimento econômico as disparidades sociais e ambientais seriam naturalmente resolvidas, foram igualmente assimilados e teorizados.

[...] entre os defensores da factível conciliação entre conservação ambiental e crescimento econômico se propagou a idéia de que só com crescimento conseguir-se-ia vencer a crise ambiental, [...] defendiam que a crise social e a pobreza, bem como a crise ambiental, seriam automaticamente vencidas quando se atingisse um determinado nível de renda per capita. Os adeptos dessa tese panglossiana baseiam-se principalmente nos estudos de Grossman e Krueger que, ao examinar a relação entre renda per capita e indicadores de degradação ambiental, concluíram que, a partir de um nível de renda, estimado por eles em oito mil dólares, ocorreria uma reversão da degradação ambiental (VEIGA, 2008 apud JATOBÁ, CIDADE e VARGAS, 2009, p. 61).

É, pois, essa racionalidade que coloca o mercado como o Messias do mundo, que se pretende desmistificar e desconstruir. Uma vez que a crise ecológica contemporânea é "[...] apenas o reflexo dessa contradição, do caráter insustentável do próprio capitalismo" (STAHEL, 1995, p. 117).

Para tal, torna-se imperativo um novo contrato social, diferente daquele proposto por Rousseau, onde a dimensão ecológica encontrava-se marginalizada e excluída, mas um novo contrato socionatural onde o homem não seja a figura central no mundo, mas parte de um todo complexo e se autoenxergue como sujeito interdependente dos ecossistemas, como um ser vivo dentre os diversos existentes. Porque o antropocentrismo moderno subjugou as outras formas de vida. É por isso que se torna mister inovar no sentido se transformar esse background capitalista, que converte o homem não em parte dos sistemas globais, mas dissociando-o, faze-o um explorador insaciável dos bens materiais finitos do planeta.

Dentro da sociedade de mercado, que induz ao consumo e à circulação de mercadorias, podem ser verificados quatro aspectos que esta sociedade insustentável produz em médio e longo prazos: 1) crescimento da população humana em condições exponenciais; 2) diminuição da base de recursos ecológicos; 3) uso de tecnologias poluentes nos sistemas produtivos e com baixa eficácia energética; e 4) um sistema de valoração social que proporciona o uso e expansão sem limites dos recursos ambientais (ROHDE, 1995).

Além disso, este autor sinaliza caracteres ainda mais insustentáveis do capitalismo, fruto do crescimento progressivo e permanente da economia, mesmo diante dos recursos esgotáveis da Terra, que são acúmulo em ritmo acelerado de matéria natural, energia e riqueza; desrespeito às limitações biofísicas; interferência nos ciclos 
biogeoquímicos elementares dos sistemas ecológicos; destruição dos sistemas de suporte a vida; e a crença exagerada na tecnologia e na ciência para resoluções e minimização dos efeitos causados pelo crescimento em curso.

Outras questões importantes para o entendimento da sustentabilidade são apontadas por Stahel (1995), quando trata da Lei da Entropia, da temporalidade dos processos naturais da Gaia, que estão diametralmente opostos à lógica de acumulação capitalista-industrial, e do resgate da política como dimensão fundamental para a construção da sustentabilidade. Sobre a Lei da Entropia, segunda Lei da Termodinâmica, aplicada aos processos econômicos possibilitam uma leitura histórica mais precisa acerca da realidade social moderna, uma vez que a entropia se refere à degradação, desgaste e deteriorização de energia no processo produtivo, onde a queima dessa energia não pode ser mais ser usada após o processo, se perde, para sempre.

Assim, "o nível entrópico seria [...] um índice de disponibilidade de energia e matéria em sua forma ordenada, ou, em termos gerais, da ordem de um sistema" (GEORDESCU-ROEGEN, 1971, p. 4-5 apud STAHEL 1995, p. 106). É, pois, urgente a inclusão da problemática da lei da entropia no pensamento econômico porque a base natural que torna possível a sustentabilidade econômica está em xeque e coloca a própria economia em condições vulneráveis e à sociedade como um todo complexo, inclusive a capacidade de absorção do ambiente no que se refere a alta entropia ou degradação entrópica (lixo e poluição), fruto do processo econômico vigente. São a sociedade em curso e a entropia, neste sentido, opostos haja vista que a primeira aponta para uma dimensão quantitativa e o segundo para uma dimensão qualitativa da vida. A problemática aqui está no fato de que há dimensões da vida que não se podem quantificar (seguindo os critérios do mercado), como a liberdade, a felicidade, o bem-estar e satisfação de uma vida realizada plenamente, que são qualidades.

O Produto Interno Bruto (PIB) ainda hoje é considerado como um dos mais importantes indicadores de progressos econômico e social, todavia por não oferecer condições de inclusão social demonstra-se insustentável ao excluir $2 / 3$ da população mundial, eliminados dos progressos da globalização. Além de indicar quantitativamente o desenvolvimento (visão economicista), não mede as condições objetivas de felicidade e bem-estar humano. E também não leva em consideração a degradação socioambiental (SACHS, LOPES e
DOWBOR, 2010). Esse indicador prende-se ao fluxo de bens e serviços oriundos do trabalho humano, desprezando o total de riquezas disponíveis (STAHEL, 1995). É nesse raciocínio que se contesta a sociedade capitalista.

No que diz respeito às temporalidades dos processos ecológicos e da sociedade moderna, nota-se um descompasso, que é algo central na discussão da sustentabilidade do desenvolvimento. Enquanto que os processos dos sistemas ecológicos acontecem numa temporalidade mais extensa e lenta em sua regulação e autorregulação, a racionalidade capitalista, marcadamente expansiva e quantitativa, busca a aceleração do tempo e da própria entropia. Esse imediatismo estrutural não respeita aos ciclos ecossistêmicos e suas capacidades de reciclagens e de recuperação, pelo emprego de tecnologias mais pesadas e potentes para maximizar a eficiência produtiva e ao progressivo uso de mais recursos ambientais e degradação ecológica e pela cultura de consumo exagerado ideologicamente posto na sociedade, como fator de inclusão social.

É ao longo dos séculos e milênios que as diferentes cadeias foram se formando, surgindo as diferentes espécies e subespécies que foram ocupando respectivamente diferentes elos na cadeia, assegurando um fluxo contínuo e um processo de reciclagem natural [...]. [...] O homem passa a produzir novos materiais e novas estruturas a uma tal velocidade, que não existem organismos capazes de decompor reciclar tais produtos (STAHEL, 1995, p. 115).

Desse modo, recursos naturais considerados renováveis, como a água e solo, por não atenderem a mesma temporalidade do modo de produção de mercado, tornam-se recursos não-renováveis, pois não existe respeito ao tempo de recuperação desses recursos pelo capital, sem contar na incapacidade dos ecossistemas se recomporem. A aceleração do tempo pelo capital refere-se a maior degradação ambiental, isto é, alta degradação entrópica.

$\mathrm{O}$ aspecto político coloca-se também como central nessa discussão. A análise da problemática ambiental dissociada de leitura mais profunda dos "fundamentos materiais, institucionais e culturais de nossa sociedade" (IDEM, p. 117) representa uma retórica vazia e infundada. É, portanto, condição elementar para a construção da sociedade sustentável uma re-criação política completa do corpo societal, sem o qual as empreitadas em busca da sustentabilidade estarão destinadas ao fracasso. Essa dimensão política é igualmente 
colocada por Lefebvre (1991), ao propor uma revolução cultural permanente da sociedade (que não se prende meramente ao caráter cultural, mas inclui os níveis econômico e político), frente ao capital, indicando, inclusive, que não há necessidade de modificação da proposta de Marx sobre esse aspecto, pois a estratégia revolucionária, que engloba o nível político ainda é atual e, por isso mesmo, pertinente.

A completa mercantilização da vida e da sociedade que se torna mercado, atravessada pelas leis do mercado, que é o maior triunfo da globalização, no raciocínio de Castel (1997), em detrimento dos equilíbrios naturais, das relações societárias e da autonomia individual, enquanto condição elementar da emancipação humana plena, é que precisa ser revista e contestada, primeiramente, se se quer pensar na sustentabilidade da sociedade, em direção construtiva da qualidade de vida (STAHEL, 1995). Essa noção de qualidade de vida, como um conceito central nas discussões da sustentabilidade se "[...] relativiza e contextualiza a questão das necessidades humanas e do processo social para satisfazê-las [...], existindo pouco avanço na sistematização e operacionalização desse conceito" (LEFF, 2001, p. 147).

Um engano normalmente praticado nas discussões da sustentabilidade toca ao fato de associá-la a fatores meramente ambientais. $\mathrm{Na}$ verdade, a sustentabilidade social é precedente à sustentabilidade ecológica, uma vez que a sustentabilidade do desenvolvimento objetiva o desenvolvimento social.

Outros temas relevantes que são normalmente ignorados nessa discussão devem ser levantados, como a ética, haja vista que a sustentabilidade não pode ser vista como um problema de caráter apenas científico, para o qual se buscam alternativas de resolução técnicas e econômicas. Apesar de ser um passo elementar, deve considerar a sabedoria e ética, não a do mercado, para formulação de metas, a vontade social e política para alcançá-las e maturidade de julgamento para percebê-las (VIEDERMAN, 1993 apud PROOPS et al., 1997).

Sintetiza o autor quatro pontos necessários para um sistema político na construção de uma economia sustentável: 1) A função do Estado é estar à frente do mercado, conduzindo-o, em lugar de segui-lo como ocorre hoje. Essa explicação é simples: a instituição Estado possui capacidade potencial de prover em longo prazo as bases necessárias para a resolução dos problemas ambientais globais. 2) Não significa dizer que o mercado será suprimido do processo, porque certamente o mercado representará a conexão de interação econômica, mas a moldura dentro do qual ele funcionará deverá ser composta pelo consenso do Estado. Isso possibilitará alteração na distribuição de renda e da riqueza socialmente produzida. Numa sociedade tida democrática, essas mudanças somente podem ser realizadas se postas no nível constitucional. 3) A participação de toda a sociedade deve ser considerada pelo sistema político no que diz respeito aos processos decisórios. Entende-se que as desigualdades tanto no campo quanto na cidade constituem empecilhos para a participação popular na consecução da sustentabilidade. 4) Um pré-requisito aditivo para uma política ambiental de sucesso é um conjunto de instituições e uma burocracia que funcione, implementando e monitorando as leis. Finaliza, dizendo que para a construção de desenvolvimento sustentável seria reducionista a idéia de considerar apenas a implementação de medidas ambientalmente adequada, mas importa existência de um sistema político e econômico estável, capaz de permitir a participação de toda a sociedade.

Contrária a essa nova racionalidade está a razão capitalista, que defende asas de liberdade ao mercado em detrimento do Estado enquanto promotor de serviços sociais. A onda neoliberal inaugurou condições mais fortes da precarização da vida em todos os aspectos, pondo em xeque o Estado keynesiano, Welfare State ou Estado de Bem-Estar Social. No entanto, nos países do Terceiro-Mundo, como o Brasil, onde nunca existiu o Estado de Bem-Estar Social, essas políticas de ajustes neoliberais vão representar redução de gastos com educação, saúde, previdência e outros, como fortes rebatimentos sobre as questões ambientais. Por ofensiva neoliberal entende-se uma nova ordem socioeconômica e política que surge em contraposição ao já decadente Estado-Providência, com medidas a serem exercidas pelos países. Também representa uma reordenação do grande capital, com vistas ao alcance de maiores níveis de lucros e cuja caracterização aponta para o desmonte do aparelho estatal e sua função social de políticas universalizantes, agora postas sob o controle do mercado.

Os resultados da aplicação da empreitada neoliberal são traduzidos em aumento de pobreza e exclusão social (desemprego, achatamento salarial, subemprego e outras formas de trabalho precarizado e desprotegido, descapitalização do trabalhador, pobreza e miséria em massa), que se tem verificado maior gravidade nos países Latino-Americanos e em outras nações pobres do mundo que nos países de capitalismo avançado. 
Pereira (2001, p. 37), assim resume a crítica do neoliberalismo ao decadente Walfare State, fundado na economia de mercado e também na ética e na política do capital ao trabalho:

$\left.1^{\circ}\right)$ - que o Estado Social é despótico porque, além de impedir a economia de funcionar, nega aos usuários dos serviços sociais oportunidade de escolher e autonomia de decisão; $2^{\circ}$ ) - que o Estado Social, comparado ao mercado é ineficiente e ineficaz na administração de recursos; $3^{\circ}$ ) - que o Estado Social é paternalista e, por isso, moralmente condenável porque incentiva a ociosidade e a dependência, [...] desestimula o capitalismo de investir; $4^{\circ}$ ) - que o Estado Social é perdulário porque gasta vultuosos recursos para obter modestos resultados; $5^{\circ}$ ) - que o Estado Social é corrupto.

Apesar disso, o "evangelho neoliberal", com orientações deliberadas pelo Consenso de Washington, que se estendeu até o fim da década de 1990, não logrou êxito pertinente as suas promessas de libertação dos países objeto de suas recomendações (SACHS, 2008, p. 29). Se as condições de pobreza e desigualdade entre indivíduos e nações e no interior destas atingiram níveis notadamente obscenos, é central quando se quer pensar a sustentabilidade sob a perspectiva crítica, holística e sistêmica, apreender que o capitalismo moderno em seus ajustes imprime uma configuração de insustentabilidade social, racionalidade econômica irresponsável e gera pressão ambiental sem precedentes sobre os limites da Gaia.

Isto se deve ao fato de uma limitação estrutural do modelo hegemônico, que o impede de promover o desenvolvimento sustentável nos moldes da sociedade de mercado (STAHEL, 1995), tal qual o é impossível promover desenvolvimento orientado pela criação oportunidades de "emprego decente" (SACHS, 2008) para a massa desempregada, promover a proteção e preservação ecológica em níveis razoáveis, bem como promoção de cidadania, qualidade de vida e equidade social.

\section{A mediação cultural como desafio para a Racionalidade Ambiental}

A Racionalidade Ambiental surge como um desafio a ser construído em nome da sobrevivência humana, em última análise, e de todos os organismos vivos. Ela se contrapõe à racionalidade capitalista dominante, de cunho cartesiano, que concedeu à ciência poderes absolutos para promover o desenvolvimento em todas as sociedades, no afã, inclusive, de substituir a própria natureza. A Racionalidade Ambiental, portanto, é uma concepção global de desenvolvimento que não apresenta modelos prontos e encerrados, mas perspectivas e princípios a serem sustentações de desenvolvimentos diversos, integradores e democráticos. O desafio que se tem é bem colocado por Leff (2001, p. 113), em sua obra Epistemologia Ambiental, em seu capítulo referente ao "Pensamento Sociológico, Racionalidade Ambiental e Transformações do Conhecimento", quando considera que a Racionalidade Ambiental é:

[...] um processo político e social que passa pelo confronto e concerto de interesses opostos, pela reorientação de tendências (dinâmica populacional, racionalidade do crescimento econômico, padrões tecnológicos, práticas de consumo); pela ruptura de obstáculos epistemológicos e barreiras institucionais; pela criação de novas formas de organização produtiva, inovação de novos métodos de pesquisa e produção de novos conceitos e conhecimentos.

Portanto, esta concepção sistêmica é uma tarefa para todos, é uma franca utopia que possui materialidade suficiente para se viabilizar. A Racionalidade Ambiental, nesta perspectiva, requer a mobilização intelectual, política, social e econômica para que tenha a possibilidade de se constituir numa alternativa à racionalidade hegemônica, de natureza capitalista. É neste sentido que Leff (2000), ao abordar a proposta do ecodesenvolvimento como desdobramento da concepção da Racionalidade Ambiental, considera, fundamentalmente, que esta viabilidade depende de uma sólida articulação entre os processos cultural, ecológico e tecnológico, na qual este último deve ser moldado pelos valores do primeiro processo e limitações do segundo processo. A complementaridade destes processos, no entender do autor, é condição para a promoção de um desenvolvimento verdadeiramente sustentável. Trata-se da substituição da produção voltada para os interesses do mercado pela produção de interesse social. E esta produção social requer tanto o conhecimento científico como o aproveitamento tecnológico para que se possa efetivá-la com eficiência.

Não se trata, assim, de uma proposta idílica, aversa aos avanços técnicos que a ciência moderna proporcionou. Trata-se, contudo, de uma reorientação da ciência a serviço da coletividade, do interesse comum. Desta forma, a mediação 
cultural assume um caráter de direcionamento do emprego tecnológico para a produção social. Outrossim, a exploração dos ecossistemas deve contemplar a capacidade de recuperação dos mesmos, ainda que haja a necessária intervenção humana para a satisfação de suas necessidades.

$\mathrm{O}$ destaque dado à cultura como um fator essencial para a promoção do desenvolvimento nos marcos da Racionalidade Ambiental se explica pelo fato de que os povos pré-capitalistas conseguiam e ainda conseguem, embora com grau de dificuldades cada vez maior, garantir sua sobrevivência e seu próprio desenvolvimento numa relação intrínseca com seu ambiente. Eles conseguem alterar este seu entorno natural ao mesmo tempo em que são influenciados por esta alteração, numa relação complementar e dialética.

As sociedades criaram seus valores, instituições e processos produtivos dentro cada lógica. Laraia (1999) aponta que a coerência destas lógicas é impossível de se apreender sem antes compreender seu próprio sistema cultural que lhe dá sustentação. E justamente esta riqueza cultural que deve ser um fator de produção estratégico para um desenvolvimento sintonizado com a Racionalidade Ambiental. A relação estreita entre a cultura e o ambiente natural para os povos chamados tradicionais pode ser verificada pelo empobrecimento destes e perda de seus valores quando o ecossistema em que se inserem é destruído pelo avanço da economia de mercado.

Por esta razão, Leff (2000) considera que a degradação ambiental conduz também à destruição cultural simbólica e material destes povos, porque sua existência e seus significados dependem do próprio ambiente em que estão inseridos.

A racionalidade capitalista, neste contexto, submete o homem, independente de sua condição social e econômica, à lógica puramente econômica. Este processo se consuma a partir do momento em que molda o indivíduo às exigências para garantir a própria sobrevivência. A este respeito temos a seguinte ponderação:

O sistema econômico em via de "racionalização" tem os meios para moldar os agentes de conformidade às suas exigências: dada a pergunta implícita ou explícita sobre o que deve ser o homem econômico para que a economia capitalista seja possível, tende-se a considerar as categorias da consciência econômica própria ao capitalista como outras tantas categorias universais, independentes das condições econômicas e sociais (BOURDIEU, 1979, p. 19).
A mediação cultural neste contexto possui um caráter estratégico para a consolidação de um desenvolvimento afinado com a concepção da racionalidade ambiental, onde as necessidades humano-sociais sejam priorizadas e não as necessidades do mercado e de elites e grupos minoritários. Essa mediação norteia o processo de construção de uma sociedade concretamente sustentável.

\section{Os novos movimentos sociais e a construção da consciência planetária ambiental}

A racionalidade dominante, promotora de um modelo de desenvolvimento que predominou nos últimos séculos, de origem acumuladora e excludente, não se impôs sem resistência em todos os espaços planetários. Em muitas épocas e lugares encontrou sociedades que insistiram em manter seu modo de vida, seus estilos étnicos. Muitas destas sociedades se tornaram importantes atores políticos na luta pelo direito de viverem conforme suas convicções. Este contraponto político, cultural e econômico cresceu significativamente nos últimos anos, constituindo-se num pólo de resistência que tem atraído a simpatia e a militância inclusive daqueles que não compõe diretamente estas sociedades, mas que se identificam com as mesmas. Neste contexto, grupos ambientalistas vêm se constituindo em movimentos sociais diversos, que abrangem classes sociais e convicções religiosas variadas, mas que tem em comum a defesa de sua cultura e do seu ecossistema. Nem mesmo os tradicionais partidos de esquerda e movimentos populares tradicionais conseguem, na atualidade, mobilizar tantas pessoas como estes novos movimentos vinculados à proposta da Racionalidade Ambiental (LEFF, 2006).

Há uma razão prévia que aparenta justificar tal distinção: os movimentos sociais de cunho ambientalista trazem em seu bojo uma proposta sistêmica baseada em sua própria experiência. Estes movimentos empreendem a luta pela democracia, contra a miséria e a exclusão social combinadas com outra lógica de desenvolvimento. Eles questionam o modelo neoliberal que foi implantado na maioria dos países periféricos do capitalismo mundial, o que resultou no desmantelamento do Estado como promotor dos serviços públicos, privatizações da coisa pública, crescimento do desemprego estrutural, sujeição das economias nacionais ao capital especulativo, aumento da pobreza, dentre outras consequências e mazelas. Leff (2006, p. 468), ao comentar estes novos movimentos sociais, pontua que 
Grande parte desses novos movimentos sociais respondem aos efeitos das políticas neoliberais, mas também ao exercício autoritário do poder por parte do Estado e à ineficiência da empresa pública e privada para dotar a sociedade de condições de vida adequadas.

Esta resistência dos movimentos ambientalistas, dos povos tradicionais e de todos os agrupamentos sociais e etnias que não abrem mão da defesa de sua cultura e modo de vida está vinculada à negação de uma modernidade baseada na racionalidade dominante. Como dito anteriormente, o desenvolvimento concentrador e excludente que a racionalidade capitalista gerou ocorreu em desrespeito à diversidade cultural e ecológica. Por esta razão, a força da cultura local e de sua identidade constituiu-se num contraponto político fundamental como luta pela sobrevivência num contexto devorador de culturas e identidades em benefício da acumulação do processo hegemônico.

Neste entendimento, há que se considerar que a reação cultural deve ser interpretada como uma autodefesa daqueles grupos e etnias que se sentem ameaçados por uma cultura pretensamente dominante. $\mathrm{E}$ a recorrência às suas raízes finda sendo uma forma de resguardo de seus valores e de seu ambiente natural (HALL, 1997). Os novos movimentos sociais, neste sentido, representam um papel político indispensável para defesa de pluralidade cultural e diversidade ecológica, equidade, justiça social e atenção aos direitos societários.

Em paralelo ao surgimento dos novos movimentos sociais, o desabrochar de uma consciência global, comprometida com Gaia, é fundamental para a construção do desenvolvimento alternativo. O compromisso com um desenvolvimento que garanta o direito de todos os povos e culturas a se desenvolverem livremente é condição para uma cidadania planetária, cujos esforços sinalizem para as gerações atuais e as vindouras - solidariedade intrageracional e intergeracional. É a "[...] ética da sustentabilidade [...]", de acordo com Bursztyn (2002, p. 11).

Este comprometimento implica o reconhecimento de que precisamos mudar as bases em que se assenta o desenvolvimento vigente, direcionado pela racionalidade capitalista. Evidentemente, precisamos conciliar o avanço científico e a aplicação tecnológica com o compromisso ético. Precisamos, como destacam Bartholo Júnior e Bursztyn (2002), simultaneamente, tanto da modernidade técnica, legada pela racionalidade de mercado, quanto da modernidade ética, imperativo fundamental da racionalidade ambiental.

Este compromisso, enfim, exige a consciência de nossa limitação e de nossa diversidade num contexto complexo, onde todos homens são interdependentes e estão, por consequência, sujeitos a todos os males que vem comprometendo nossa morada planetária. A este respeito Morin e Kern (2003, p. 178) assim se manifestam em sua obra chamada Terra Pátria:

Precisamos fundar a solidariedade humana não mais numa ilusória salvação terrestre, mas na consciência de nossa perdição, na consciência de nossa pertença ao complexo comum tecido pela era planetária, na consciência de nossos problemas comuns de vida ou de morte, na consciência da situação agônica de nosso começo de milênio.

A nova consciência planetária, diante da atual crise socioambiental em escala mundial, é um imperativo ético para que todas as sociedades humanas mobilizem esforços em todos os aspectos para a construção da sustentabilidade do desenvolvimento diferente das propostas insustentáveis que temos hoje.

\section{CONSIDERAÇÕES FINAIS}

\section{Para não concluir}

Em Leff (2000) e Sachs (2008) percebe-se o otimismo conjugado com a possibilidade de construção de uma racionalidade ambiental alternativa, com vista a substituir a racionalidade que dá tom às práticas produtivas aniquiladoras dos povos, das culturas, dos organismos vivos e do ambiente. Nesses autores, bem como em Santos (2008) e Morin (2011), estão explícitas as prospecções para a construção de uma Epistemologia do Sul, onde os países pobres podem potencialmente mostrar e propor às nações "civilizadas" do primeiro mundo outra forma de desenvolvimento em que as dimensões social, ecológica e econômica sejam mediadas pela cultura, pelas particularidades de cada ecossistema.

Essa nova epistemologia considerará as pessoas como sujeitos interdependentes em relação às condições ecossistêmicas e ao aspecto econômico, como parte do processo e nunca o único aspecto a ser considerado. Uma nova racionalidade de desenvolvimento diferente daquela que temos atualmente.

O desconforto proveniente do processo glo- 
balizatório sofrido pelos países subdesenvolvidos decorre da própria lógica de crise permanente do capitalismo. Esse cenário de crescente insatisfação nos países pobres conduzirá gradualmente a um processo de mudança cujo ritmo e forma não serão sincrônicos. Desse modo, as mudanças para uma nova racionalidade global, que seja includente e democrática, serão viabilizadas a partir do sofrimento dos países subdesenvolvidos, cabendo a estes o protagonismo desse processo, que será, portanto, de baixo para cima (SANTOS, 2001). Nesse sentido, a mudança ocorrerá por meio da política, no entanto tal mudança não pode ser oriunda

[...] dos Estados Unidos ou da Europa. Virá dos pobres, dos 'primitivos' e 'atrasados', como nós, do Terceiro Mundo, somos considerados. Estas não podem vir das classes obesas. Estas não podem ver muito. São os pobres os detentores do futuro (SANTOS et al., 2000, p. 66).

Contextualizando à luz de tais análises, o papel das nações empobrecidas do Terceiro-Mundo, particularmente da América Latina, é semelhante ao papel do Escravo, em sua relação dialética com o Senhor, como se referiu Hegel em sua Fenomenologia do Espírito, quando diz que o Escravo tem um duplo papel: libertar a si próprio das cadeias e da opressão a que está submetido, mas também libertar o seu Senhor, mostrando-o a liberdade que o domínio de si próprio promove.

Esta, talvez, seja a mais importante missão sociopolítica das "nações subdesenvolvidas" neste século e quem sabe pelos próximos séculos: libertar-se a si mesmos das cadeias do pensamento dominante, propondo outra epistemologia alternativa e ao mesmo tempo libertar aqueles que historicamente impõem degradantes modalidades de desenvolvimento, cujos resultados podem ser descritos como níveis insustentáveis de precariedade humana e desrespeito aos ciclos ecológicos do Planeta, comprometendo a capacidade de existência atual e vindoura da Gaia e, por conseguinte, de toda humanidade.

\section{AGRADECIMENTOS}

Ao Conselho Nacional de Desenvolvimento Científico e Tecnológico (CNPq), por financiar parcialmente este trabalho.

\section{REFERÊNCIAS}

BARTHOLO JÚNIOR, Roberto dos Santos; BURSZTYN, Marcel. Prudência e utopismo: ciência e educação para a sustentabilidade. In: BURSZTYN, Marcel (Org.). Ciência, ética e sustentabilidade: desafios ao novo século. São Paulo: Cortez, 2002.

\section{BOURDIEU, Pierre. $\mathbf{O}$ desencantamento do} mundo: estruturas econômicas e estruturas temporais. São Paulo: Perspectiva, 1979.

BURSZTYN, Marcel. Introdução. In: BURSZTYN, Marcel (Org.). Ciência, ética e sustentabilidade: desafios ao novo século. São Paulo: Cortez, 2002.

CASTEL, Robert. As transformações da questão social. In: WANDERLEY, Luiz Eduardo et al. Desigualdade e a questão social. São Paulo: Cortez; EDUC, 1997.

HALL, Stuart. A identidade cultural na pós-modernidade. Rio de Janeiro: DP\&A, 1997.

IANNI, Octávio. A questão social. Revista São Paulo em Perspectiva. São Paulo, v. 5, n. 1, jan/mar. 1991.

JATOBÁ, Sérgio Ulisses Silva; CIDADE, Lúcia Cony Faria; VARGAS, Glória Maria. Ecologismo, Ambientalismo e Ecologia Política: diferentes visões da sustentabilidade e do território. Sociedade e

Estado. Brasília, v. 24, n. 1, p. 47-87, jan./abr. 2009.

LARAIA, Roque de Barros. Cultura: um conceito antropológico. Rio de Janeiro: Jorge Zahar, 1999.

\section{LEFEBVRE, Henri. A vida cotidiana no mundo moderno. São Paulo: Ática, 1991.}

LEFF, Enrique. Racionalidade ambiental, produtividade ecotecnológica e manejo integrado de recursos. In: LEFF, Enrique. Ecologia, capital e cultura: racionalidade ambiental, democracia participativa e desenvolvimento sustentável. Tradução Jorge Esteves da Silva. Blumenau: Editora da FURB, 2000.

Pensamento sociológico, racionalidade ambiental e transformações do conhecimento. In: LEFF, Henrique. Epistemologia ambiental. Tradução Sandra Valenzuela. São Paulo: Cortez, 2001.

O movimento ambiental pela reapropriação social da natureza: seringueiros, zapatistas, afro-des- 
cendentes e povos indígenas na América Latina. In: LEFF, Enrique. Racionalidade Ambiental: a reapropriação social da natureza. Tradução Luís Carlos Cabral. Rio de Janeiro: Civilização Brasileira, 2006.

LOVELOCK, James. Prefácio: algo de sórdido na estufa e Introdução. In: LOVELOCK, James. Gaia: cura para um planeta doente. Tradução Aleph Teruya Eichemberg e Newton Roberval Eichemberg. São Paulo: Cultrix, 2006.

MORIN, Edgar; KERN, Anne Brigitte. Terra-Pátria. 4. ed. Tradução Paulo Azevedo Neves da Silva. Porto Alegre: Sulina, 2003.

MORIN, Edgar. Para um pensamento do sul. In: Encontro Internacional para um Pensamento do Sul: diálogos com Edgar Morin, 2011; Anais... Rio de Janeiro: SESC, Departamento Nacional, 2011.

PEREIRA, Potyara Amazoneida Pereira. Estado, regulação social e controle democrático. In: BRAVO, M. E. S; PEREIRA, P. A. P. Política social e controle democrático. São Paulo: Cortez; Rio de Janeiro: UERJ, 2001.

PROOPS, John et al. Realizando um mundo sustentável e o papel do sistema politico na consecução de uma economia sustentável. In: CAVALCANTI, Clóvis (Org.) Meio ambiente, desenvolvimento sustentável e políticas públicas. São Paulo: Cortez; Recife: Fundação Joaquim Nabuco, 1997.

ROHDE, Geraldo Mário. Mudanças de paradigma e desenvolvimento sustentado. In: CAVALCANTI, Clovis (Org.) Desenvolvimento e natureza: estudos para uma sociedade sustentável. São Paulo: Cortez, 1995.

SACHS, Ignacy. Desenvolvimento: includente, sustentável e sustentado. Rio de Janeiro: Garamond, 2004.

Caminhos para o desenvolvimento susten-

tável. 3. ed. Rio de Janeiro: Garamond, 2008.

SACHS, Ignacy; LOPES, Carlos; e DOWBOR, Ladislau. Crises e oportunidades em tempos de mudança. Economia global e gestão, v.15, n.1. 2010. Disponível em: <http://www.scielo.gpeari. mctes.pt/scielo.php?script $=$ sci_arttext\&pid $=$ S0873$-74442010000100008 \& \operatorname{lng}=$ en\&nrm $=$ iso $>$. Acesso em: 26 mar. 2013.
SANTOS, Boaventura de Sousa. A filosofia à venda, a douta ignorância e a aposta de Pascal. Revista Crítica de Ciências Sociais, 80, p.11-43. mar. 2008. Disponível em: <http://www.ces.uc.pt/myces/UserFiles/livros/47 Douta\%20Ignorancia.pdf $>$. Acesso em: 13 set. 2012.

SANTOS, Milton et al. Território e sociedade: entrevista com Milton Santos. São Paulo: Editora Fundação Perseu Abramo, 2000.

SANTOS, Milton. Por uma outra globalização: do pensamento único à consciência universal. 6. ed. Rio de Janeiro: Record, 2001.

STAHEL, Andri Werner. Capitalismo e entropia: os aspectos ideológicos de uma contradição e a busca de alternativas sustentáveis. In: CAVALCANTI, Clovis (Org.) Desenvolvimento e natureza: estudos para uma sociedade sustentável. São Paulo: Cortez, 1995. 